\title{
Effect of vegetation and waterbody on the garden city concept: an evaluation study using a newly developed city, Putrajaya, Malaysia
}

\begin{abstract}
The garden city concept was adopted in the development of a new tropical city, Putrajaya, aimed at mitigating the effect of urban thermal modification associated with urbanisation, such as urban heat island (UHI). WRF/Noah/UCM coupled system was used to estimate the urban environment over the area and the individual thermal contributions of natural land use classes (vegetation and waterbody). A control experiment including all land use types describing the urban conditions of Putrajaya city agreed well with the observations in the region. A series of experiments was then conducted, in which vegetation and waterbody were successively replaced with an urban land use type, providing the basis for an assessment of their respective effect on urban thermal mitigation. Surface energy components, 2-m air temperature (T2m) and mixing ratio (Q2m), relative humidity (RH) and UHI intensity (UHII) showed variations for each land use class. Overall, an increase in urban surfaces caused a corresponding increase in the thermal conditions of the city. Conversely, waterbody and vegetation induced a daily reduction of 0.14 and $0.39{ }^{\circ} \mathrm{C}$ of $\mathrm{T} 2 \mathrm{~m}$, respectively. RH, UHI and $\mathrm{T} 2 \mathrm{~m}$ also showed variations with urban fractions. A thermal reduction effect of vegetation is visible during mornings and nights, while that of water is minimally shown during daytime. However, during nights and mornings, canopy layer thermal conditions above waterbody remain relatively high, with a rather undesirable effect on the surrounding microclimate, because of its high heat capacity and thermal inertia.
\end{abstract}

Keyword: Garden city concept; WRF/Noah/UCM; Urban heat island; Putrajaya; Waterbody and vegetation; Tropical city 